\title{
Notiz zur Kenntnis des Novains.
}

\author{
Von
}

Fr. Katscher.

(Aus dem physiologischen Institut der Universität Marburg.)

(Der Redaktion zugegangen am 7. November 1906.)

Vor kurzem ${ }^{1)}$ habe ich gezeigt, daß das Novain durch Desillation mit Baryt gespalten wird. Man kann daraus den gesamten Sticktoff in Form von Trimethylamin abdestillieren. Aber auch der Destiationsrückstand enthält ein charakteristisches Spaltungsprodukt des bvains, dasselbe ist wahrschcinlich Crotonsäure.

Um die Säure darzustellen, nimmt man den Rückstand mitheißem Wasser auf, entfernt das überschüssige Baryum durch Kohlensäue, engt die Flüssigkeit stark ein und übersäuert sie mit Schwefelsäus. Sie wird darauf mit Äther erschöpft, der nach dem Verdunsten die eutlich nach Buttersäure riechende Säure zurückläßt.

1) Diese Zeitschrift, Bd. XLIX, S. 47.

\section{Berichtigung. \\ Von}

K. Mays.

(Der Redaktion zugegangen am 7. Novomber 1906.)

In meiner Arbeit über die Wirkung des frischen Hundepakreassaftes (Diese Zeitschrift, Bd. XLIX, S. 188) habe ich S. 192, 197 ud 201 eine Arbeit irrtümlicherweise E. Fischer und P. Bergell zugescrieben, während dieselbe von E. Fischer und E. Abderhalden stamr. 